\title{
Non-smoking worksites in the residential construction sector: using an online forum to study perspectives and practices
}

\author{
Susan J Bondy, ${ }^{1}$ Kim L Bercovitz ${ }^{2}$
}

${ }^{1}$ University of Toronto, Dalla Lana School of Public Health, and Ontario Tobacco Research Unit, Toronto, Ontario, Canada ${ }^{2}$ University of Toronto, Dalla Lana School of Public Health, Ontario Tobacco Research Unit, and The Research Doctor Inc, Toronto, Ontario, Canada

\section{Correspondence to}

Susan Bondy, University of Toronto, Dalla Lana School of Public Health, Sixth Floor, 155 College Street, Toronto, Ontario M5T 3M7, Canada: sue.bondy@utoronto.ca

Received 14 June 2010 Accepted 8 October 2010 Published Online First 29 November 2010

\section{(2) UNLOCK:}

This paper is freely available online under the BMJ Journals unlocked scheme, see http:// tobaccocontrol.bmj.com/site/ about/unlocked.xhtml

\begin{abstract}
Objectives Blue-collar workers are a recognised priority for tobacco control. Construction workers have very high smoking rates and are difficult to study and reach with interventions promoting smoke-free workplaces and cessation. The objectives of this study were to explore the smoking-related social climate in the North American residential construction sector and to identify potential barriers and facilitators to creating smokefree worksites. Methods The data source used was a popular internet forum on home building. Participants included a broad and unselected population of employers, employees and freelance tradespersons working in residential construction. The forum archive contained 10 years of discourse on the subjects of smoking, workplace secondhand smoke and smoking restrictions on construction sites. Qualitative data analysis methods were used to describe major and minor discussion themes relevant to workplace smoking culture and policies in this sector.
\end{abstract}

Results Participants described considerable tension between smoking and non-smoking tradespersons, but there was also much interpersonal support for cessation and support for non-smokers' rights. Employers and employees described efforts to make construction sites smoke free, and a movement towards preferential hiring of non-smoking tradespersons was discussed. Board participants wanted detailed scientific evidence on secondhand smoke exposure levels and risk thresholds, particularly in open-air workplaces.

Conclusions Experience with success of smoking bans in other challenging workplaces can be applied to the construction sector. Potential movement of smokers out of the workforce represents a challenge for public health systems to ensure equitable access to cessation supports and services.

\section{INTRODUCTION}

Blue-collar workers have high rates of smoking and are a priority for tobacco control. ${ }^{1-6}$ In 1997-2004, American construction workers had the highest smoking rates by occupational group at 39\% (versus an average of $25 \%$ among all employees in the sample); all 13 occupations with prevalence over $30 \%$ were blue collar. ${ }^{4}$ Data for $2006-2008^{6}$ reported $43 \%$ prevalence in construction and extraction compared to a low of $12 \%$ for the education sector. Canadian data show similar disparities. $^{78}$

Blue-collar workers are not uniformly low income or unskilled, and smoking differences by occupation persist after considering age, race, income and education, ${ }^{3} 910$ making the workplace a focus for intervention. ${ }^{9}{ }^{11-15}$ Construction workers in the residential sector (roughly $30 \%$ of American construction activity ${ }^{16}$ ) are poorly studied. These workers are often temporary employees, and work in small owner-operated companies with limited capacity to offer health promotion programs. ${ }^{17} 18$ Therefore, these workers are difficult to reach for research and intervention. ${ }^{18-20}$

The objectives of this research were to understand the social context and smoking restrictions that exist in this work sector, and to identify opportunities and barriers to achieving smoke-free workplaces in residential construction. Qualitative data analysis was used to describe the views and experiences of an online population of individuals working in residential home construction.

\section{METHODS}

\section{Data source}

The data source used was the online discussion forum Breaktime, ${ }^{21}$ associated with the magazine Fine Homebuilding. The board is open to the public and registrants are told it is 'not private'. Messages appear automatically, but are often moved to Woodshed Tavern, a heading provided for off-topic, off-colour or personal content. This analysis reviewed messages (archived online) from December 1998 to May 2010, inclusive. Ethical approval was received from University of Toronto. Taunton Press (the site owners) gave permission to use copyright material for this research. Searching this board and the internet found six other forums related to construction; none included information on smoking.

\section{Participants' characteristics}

According to unpublished marketing data ${ }^{22}$ (from 2009; personal communication, M Robinson, Taunton Press, 8 September 2010), Finehomebuilding. com received 330000 unique visitors per month; $89 \%$ were men; the average age was 50; and the average income was US\$126000. Data specific to the Breaktime forum are not available. In a pilot stage (August-September, 2009), we found over 250 unique (anonymous) usernames in relevant discussions and looked for demographics and employment data in optional user profiles and messages. The vast majority were men who worked as contractors, framers, roofers, plumbers, electricians and specialists, in USA and Canada. Participants included owners, regular and freelance workers. Job sites described were mostly single-family homes and small multiunit residences with wide variation in value, and suburban through to remote in location. 


\section{Data retrieval}

Both authors subscribed to the site, but posted no messages. We searched subject headings, thread titles and message content for keywords related to smoking and cessation (eg, smoke/smoking, tobacco, cigarette, nicotine, secondhand smoke, SHS, quit smoking, 'cold turkey') alone and with work-related keywords (eg, job, work, employee, hire). When a relevant message was found, the entire thread was examined. Over a 1000 smokingrelated messages appeared under several headings (eg, General Discussions, Business and Woodshed Tavern) in smoking-specific threads (eg, smokers on the job site; secondhand smoke; smoking issue; fired for smoking; freedom of choice; I quit smoking; help to quit smoking) and other threads. Relevant messages were copied for manual analysis. Iterative searching stopped when new keywords found no new threads or themes. We excluded all comments on smoking in general, SHS elsewhere (eg, bars), smokeless tobacco and marijuana.

\section{Data analysis}

The goal of the analysis was to describe the attitudes and experiences of participants related to workplace smoking. ${ }^{23}$ Qualitative methods were used to organise and analyse textual data by systematically coding them into meaningful categories and themes. Strauss and Corbin's 24 procedures for coding qualitative data (open, axial and selective coding) were applied using an inductive process. Semiquantitative methods (eg, counts by theme) and a priori hypotheses were not used. We sought to identify patterns of consensus and disagreement. Open coding involved reviewing the discussion posts, asking questions of the data (eg, 'what is this?', 'what does it mean?', 'who is the discussant?') and breaking data into discrete categories compared for similarities and differences. Next, axial coding entailed subcoding around each category, to establish linkages between categories and their subcategories. A coding scheme was developed with 33 subcodes or subcategories. In selective coding, inter-related categories were grouped under thematic headings. Identified themes are presented with illustrative quotes changed only for typographical errors. Both authors identified keywords and verified search completeness Categories, themes and illustrative quotes were negotiated ${ }^{26}$ between authors until agreement was reached.

\section{RESULTS}

\section{Major and minor content themes}

Content is presented here under four major themes, with variable numbers of subthemes, and further categories or examples within subthemes.

\section{Major theme \\ Conflict over smoking}

Smoking on building sites was a contentious issue. A polemic was observed characterised by negative attitudes, stereotypes, and conflict between smoking and non-smoking builders. Table 1 presents selected subthemes.

Harsh comments about smoking smokers were made by non-smokers and recounted by smokers. Similarly, pejorative comments about non-smokers were found, including accusations of intolerance, discrimination and of being hypocritical.

It's a poor unhealthy habit that I have attempted to quit before. Until I do, I don't feel I have to apologize to every non-smoker who comes along or considers myself a second class citizen.

Statements varied from reasoned to aggressive. Many, arguably, were humorous.

All smokers should be shot on sight.

When one asks if I mind if they smoke, I just say... mind if I fart?

Several smokers said they had no wish to affront non-smokers and respected non-smokers' rights. A related subtheme related to

Table 1 Subthemes related to arguments and interactions between smokers and non-smokers at work

\section{Theme and comments}

A question of rights:

Explicit debate about whether smoking is a right

Mixed opinions on the entitlement of non-smokers

to a completely smoke-free workplace

\section{Tolerance and intolerance}

\section{Addiction:}

Acknowledgement of addiction

Variable attitudes regarding tolerance of addictive behaviour

You and I smell different(ly):

Disagreement over the smell per se and its aversiveness

Inadequate justification:

Smell as insufficient justification for restrictions

Protests that health arguments are used to justify preferences,

and descriptions of an anti-smoking stance as political correctness,

a movement, or belief system

Advice to speak up and how:

Encouragement to raise issues with supervisors

Expressions of thanks for advice on how to broach the subject.

Illustrative quotations

No[,] smoking is not a protected right. In fact, smokers usually find themselves the constant source of violating someone else's rights by subjecting them to smoke.

A person has a right to choose to smoke, but, other individuals have the right not to be exposed to second hand smoke.

When you said that you didn't want anyone smoking 'anywhere near' you, you seemed to be stepping over the line where you have every right to be in control (in your home, car, etc) to areas where your desires may be in conflict with someone else's desires. At that point, it becomes a situation requiring some negotiation and compromise.

Intolerant? I just like clean air. I like my clean air space...I choose not to smoke and will not be put in a position where I have to put up with it because I might hurt somebody's precious feelings.

I don't smoke either, but this intolerant attitude makes me want to puke.

I know it's addictive. But there's help out there. [...] You still stink. [...]

Maybe you don't understand why someone can let cigarettes rule their lives, but that statement says more about you and your understanding of addiction than it does about smokers.

Maybe because your olfactory senses are shot, you don't realise how bad it smells. I don't care to talk with someone after they have a smoke because it's still on their breath. It's on your clothes. In your hair, your vehicle, your very presence. It gets on your grandchildren when they come for a visit. It reeks. As a former smoker, my opinion is (was) that if it doesn't affect anyone else, it should be my right to poison my own damn self anytime I saw fit. When it begins to affect someone else's health or even their comfort or smell, that infringes on THEIR right not to smell my smoke. [...]

[...] he really doesn't care about 'health issues' but just wants to blow a smokescreen over the fact his real objection to smoking is that he doesn't like it. He is entitled to not like tobacco smoke. But he is NOT entitled to be intolerant of it unless he does nothing that annoys anyone else.

You have every right to complain on a health basis. You have no such right to complain about a bad smell.

Try and play nice. It will probably work better than threats. Besides, their hammer is probably as big as yours and then what have you gained?

Tread lightly when dealing with smokers, but I would do it anyway.

Speak up, say something (without being preachy; smokers won't react well to that, trust me) and if they're good guys, they'll stop in your general vicinity. 
how non-smokers could speak up without creating conflict (see table 1).

\section{Critical discussion about secondhand smoke}

Most speakers accepted that smoking was harmful. A small number of participants were dismissive of the health risk due to active smoking; these posts tended to be rebutted quickly.

It's been known for a long time that smoking causes cancer and a lot of other diseases like weakening blood vessels, stroke, heart disease, etc. Cigarettes killed both of my parents and it's not something I take lightly.

In contrast, many smokers and non-smokers, alike, questioned the significance of risk from SHS at work, especially from SHS exposure outdoors.

Don't give me that tired old bit about second hand smoke. Sure, second hand smoke is dangerous. Under current rules, the only place smokers can smoke is outside, so a smoker really has to work to subject someone else to it (other than subjecting your kids which I agree is unacceptable).

If some rabid anti-smoker was working with me and complained about secondhand smoke in an open air building, I would have to laugh. With all the noxious fumes, dust and odors of a typical jobsite, sometimes cigarette smoke is pleasant by comparison.

Similarly, posters debated whether smelling smoke was relevant to health.

You aren't going to get lung cancer from smelling their smoke, despite the hype, just as we should probably prohibit fireplaces, because I can smell that sweet oak smoke when I go outside now. [...] All I can say is, chill out. Tell them to go outside and worry about other stuff.

Very few posts discussed SHS with explicit reference to regulated occupational exposures.

Why protect against one substance and on a regular basis willingly expose yourself to another? It makes no common sense.

However, many participants said that SHS was no worse than commonplace exposures (eg, dust or exhaust).

It's a chemical that they find pleasurable and relaxing, it causes me no more harm than the exhaust from my truck in small doses. Let them be.

Some participants expressed interest in scientific data on risk thresholds for SHS exposure.

The issue of second hand smoke is more problematic. How much exposure is required to create a health hazard? I've never seen any studies that define a level of exposure that is safe or unsafe. It's similar to exposure to ionizing radiation. What's the threshold?

Participants offered website links to reports on SHS effects and risk thresholds from sources such as Science Daily and the National Cancer Institute.

\section{Experiences with smoking at work}

This theme and the following were closely linked. This theme pertained to experiences with smoking on the job, and whether this was problematic. Problem areas identified included safety, litter and conflict (see table 2). Former smokers and those trying to quit reported that the presence of smokers at work was difficult for them. In the same conversations, several participants commented that problems weren't inevitable and could be prevented through courtesy or voluntary action. Most posters agreed with at least some measures to separate smokers and non-smokers at work.
Discussion of formal smoking restrictions

Messages related to this theme described rules that employers had adopted, why they did this and what was effective. Subthemes are presented below.

\section{Subtheme: motivations for smoking policies}

Rules were often made to avoid the problems discussed above. In addition, several people made reference to disapproval of smoking by customers. One employer mentioned that his crew does not smoke while talking to the customer unless they smoke.

I don't allow smoking on my projects, no exceptions, it's right there in the request for a bid, if you can't handle it then don't bother working on my job. Smoking outside is permitted, nothing personal, just common courtesy, who wants to move into a brand new home and have it smell like a bar.

I smoke. And if someone was doing finish in my house smoking they would not be back. Even if the HO [home owner] didn't admit to minding they did. I can't smoke at work and I work outside; smokes stay in car, at the shop. I think most any company worth working for has gone this way.

We did not find many employers who said explicitly that they had restricted smoking to reduce their own health insurance costs. However, smoking and SHS were discussed often in general discussions about health insurance (not explicitly reviewed).

The company I work for recently banned all use of tobacco while on the job. The reason was purely economic. Tobacco use was responsible for about $20 \%$ of the cost of our medical insurance.

Finally, a few participants stated that workplace legislation should apply to construction sites to create equality with other workplaces:

Ohio recently passed a law outlawing smoking in the workplace... I don't think a home as a work site should be an exception.

In this day and age where cigarettes are banned in most workplaces, why are the trades still subjected to this offensive drug?

Speakers were not unanimous in support for legislation, however. Many speakers described how voluntary measures could prevent meaningful SHS exposure (see previous theme). One speaker explicitly stated a preference for voluntary measures over government intervention.

\section{Subtheme: the need for commitment from bosses}

Several speakers showed that they felt it was important for the boss to demonstrate commitment to smoking restrictions, and that non-smokers wanted employers to take a stand to defend non-smokers.

In my line of work I tend to take over a section of the house during construction. I make it known that this area is my area, not to be smoked in. On the few occasions that I've had people light up, I remind them. Once. You don't have to like it. I don't care if you don't like it. You won't smoke in my work area.

One worker directly asked board participants for advice to address smoking at work (versus change jobs) and was encouraged to speak with his boss.

I think I will talk to the boss and tell him what I can and cannot work with, and then the answer will be revealed.

\section{Subtheme: the need for enforcement}

Several discussants recommended signage, although one stated that signs aren't helpful if 'only there for insurance purposes' and not enforced. Many workers and employers recommended 
Table 2 Themes related to problems arising from smoking on construction worksites, and voluntary measures that reduced or ameliorated problems Theme and comments

Illustrative quotations

Problems arising

Fires and safety:

Fires from cigarette butts dropped out of windows, onto grounds and into trash barrels

Other unsafe practices while smoking, such as on ladders

Breaks and productivity:

Effects of smoke breaks and nicotine withdrawal on productivity

Resentment by non-smokers

Non-smokers appearing better to the boss

Litter and unprofessional appearance:

Litter, damage and unsightliness of smoking

Interpersonal conflict:

Examples of conflict between smoking and non-smoking coworkers and occasions where smokers and non-smokers had found it difficult to share a workspace

The need for negotiation between individuals, in the absence of rules or enforcement Difficult for former smokers and those trying to quit:

Smell of smoke, access to cigarettes and presence of smokers at work as triggers for withdrawal and relapse

Efforts made by smokers to limit litter and secondhand smoke (SHS) exposure:

Statements that problems such as littering were not necessary consequences of smoking at work

Courteous efforts/and need for recognition of accommodations

Maintaining personal space:

Maintaining space between smokers and non-smokers as an important, or sufficient means to prevent SHS exposure and conflict
Smoking described as unprofessional

Voluntary measures which reduce problems

There's a section where we're working that the garage wall is open to the living room I'm standing there talking to the builder and I smelled something burning and we looked over near the garage wall and there was smoke coming up and it turns out that the BRAINLESS PIECE OF SH!T [tradesperson] threw his cigarette butt into the garage and it landed on a towel and the towel caught on fire.

He takes his cig butt and tosses it under the chop box cause he saw me walking around the corner. The fine saw dust under the chopper went up in a blaze in 2 seconds. Another low life scumbag like the [tradesperson] on the job I was on! NO EXCUSE AT ALL and it's NOT AN ACCIDENT EITHER!!!!!!

I figure $u$ get about $7 \mathrm{hrs}$ of work out of a smoker in average day. Why should a nonsmoker have to work more cuz he doesn't have a habit that requires a break every half hour?

Smoke breaks don't mean tools down.

It just makes those of us who don't smoke look better. When the smokers are lighting up a dozen times a day we keep working, and it might happen that we bang hammers a little more often to highlight who's working and who's not.

I can stand the smell (would vote against it) but it's the trash that comes with it! Drives me nuts! Wrappers, ends, boxes and the like. Keep the trash where it belongs! And don't smoke in my truck!!

I still can't believe that smokers think that they have the right to smoke where they want and throw the butts on the floor or ground like a bunch of disgusting pigs.

One kid helper kept lighting up as we're working shoulder to shoulder. I told him those cigarettes were gonna be the death of him. Because if he didn't put that damn thing out was gonna kill him.

I told the guy to either get away from me with his cig or I was gonna rearrange his face. Sure would be easy to bum a smoke or two and become a regular smoker again. I don't mind having sporadic contact with smokers, just can't work right next to one. It's not that smokers deny the stink of cigarettes, it's that they just have no sense of smell! I quit for 2 weeks once and-man did cigarettes really stink at that time...

I smoke... it's my only vice. I do it outside... always... and always have a soda can for my butts, which goes in my own trash bag.

Daily jobsite cleanliness. No debate here-JUST DO IT!

We spend more waking hours with our coworkers and other people's homes than we do with our families at our own homes (generally speaking) and I think we owe it to everyone to be professional and respectful.

It annoys me when yet another person I don't know lectures me about my lack of consideration because they saw me holding my cigarette and lighter while on my way out to stand in the rain and smoke.

It is something a nonsmoker can easily avoid by the simple expediency of moving away from the smoker. I'll accommodate you by not subjecting you to my habit other than the way I smell and you can accommodate me by just leaving me alone with my cigarette Personally, I don't want anyone within arms length of me except the wife, it's my personal space and unless you are giving me life support, I don't want anyone close enough to smell their breath...period.

enforcement measures including fines for smoking and billing individual smokers for costs of litter or damage. Several participants recommended that one accept that smoking will occur and take measures such as fire-safe garbage containers and separate smoking areas for lunch and breaks.

Smoking is more than a bad habit. It is a way of life sometimes and very addictive. These smokers ain't gonna just 'abide by the rule'. They will sneak a smoke whenever and wherever they can. If nothing else, you will

see them taking a bathroom break every few minutes.

\section{Subtheme: the need to define outdoor space}

Speakers asked and answered questions about when any building under construction went from being outdoor to indoor space. Suggested points of demarcation varied and included: 'no smoking at any stage of construction', 'once windows are installed', 'once insulation is installed', 'after the drywall goes up' and 'after paint and floor finishes are in place'.

\section{Subtheme: Discussion on selective hiring of non-smokers}

Several participants said that if contractors are really concerned about smoking they should hire non-smokers. Several gave advice on this.
[Former smoker] Your best bet is to hire non-smokers. Ever add up how many idle minutes a smoker gets in a day? You can't work when your hands are busy with your 'drugs'.

Stand behind it!! No matter who are the best hands, subs, salesmen. Show us what you're made of and say no to smokers entirely!!! Then we will know how strong you are in a pinch.

Related to this were discussions of discrimination. Suggestions were made to state 'non-smoking job site' in job advertisements

I think that if you look into the Equal Opportunity Employment guidelines, not hiring a smoker isn't discrimination. It's not a race, creed, sexual orientation or a disability. It's an addiction and I don't remember seeing that it's mandatory that someone with an addiction be hired when someone without one is available.

The feasibility of hiring non-smokers was also discussed, including references to high prevalence of smoking among trades in some areas versus a good supply of qualified non-smokers in others.

If you truly wish to avoid all smokers in this industry, you are going to be hard pressed to find help/subs. 


\section{Distribution of the relevant content over time}

Messages appeared throughout the study time period, but the volume was unevenly distributed. Sparring between smokers and non-smokers was found over the whole 10-year period. The most active discussions regarding the importance of secondhand smoke on job sites were in 2000 and in 2005. Discussion about formal restrictions peaked in 2005 as did the discussion of hiring non-smokers. In a 2005 thread on the subject of advertising for non-smokers, one person indicated feeling that the social climate had changed in favour of hiring non-smokers.

\section{An interesting thread...........no doubt. Interesting because about 2 yrs ago I started a similar thread and was damn near crucified by the smokers on line. Seems like a reversal in the thought process going on here. Verrrrry interesting!}

In 2009, several messages listed smoking policies among standard content for bids, contracts and job ads, and these received no reaction or comments with respect to smoking. In the most recent 2 years of data, smoking was more commonly mentioned within political debate about proposed changes in US health insurance, which was not the focus of this research.

\section{DISCUSSION}

No uniform acceptance of smoking was observed, but rather a polemic between smoking and non-smoking residential construction workers. We also found evidence that many employers had adopted smoking restrictions, and several had taken steps to hire non-smokers.

This study has several limitations. First, this is a convenience sample; we could not collect demographic data from participants and Taunton Press could provide only limited data from unpublished marketing research, which we cannot study for methods and response rates. Study subjects have higher than average income levels, even though incomes in construction are higher than the average for all industries, particularly for skilled technicians. ${ }^{27}$ Our findings may be most relevant to skilled tradespersons, owners and those with white-collar clients. One strength of this study is the absence of criteria which have excluded some workers from previous studies, such as union or business organisation membership, or a minimum of 50 employees, ${ }^{192028}$ as two-thirds of construction workers work in companies with 5 or fewer employees. ${ }^{27}$ This study also complements qualitative studies of blue-collar workers who have agreed to participate in research or prevention programmes. These situations present anti-tobacco demand characteristics and will select for smokers more open to cessation.

Data for this study came from a 10-year period, over which time the participants may have experienced many changes related to smoking restrictions and general attitudes. ${ }^{20}$ However, our ability to consider trends in time was limited. We did not perform quantitative tests for trends by time. This analysis would have poor statistical power to detect trends, given the total volume of information and its unequal distribution over time. Such analysis could also be misleading when applied to discussion board content that remains online. Board participants often search content before posting a question, and may avoid repeating what has been said. Therefore, changes in the numbers of positive or negative posts, over time, may not reflect real changes in attitudes. Changes in attitudes expressed online cannot be linked to actual changes in policies affecting the speakers. It cannot be known where individuals work and which legislation or voluntary association guidelines affect them directly, and when policy changes would have affected different speakers.
Smoking and non-smoking workers often represent conflicting self-interest groups. Work with trade unions ${ }^{11}{ }^{20}$ has shown that not wanting to take sides can inhibit leaders from establishing smoke-free policies, but also shows acceptance of policies after consultation. Studies in several settings suggest conflict is reduced when complete bans replace partial ones, ${ }^{29-31}$ which is plausible through reduced need for interpersonal negotiation, and distancing smokers from smoking cues which trigger cravings. Regarding the significance of observed conflict, some name calling was likely of humorous intent, as described in various workplaces, particularly between men. ${ }^{32}$ Humour may diffuse tension and allow discussion of difficult subjects, or denigrate opposing voices. ${ }^{33}$ Argumentation is also common resistance behaviour in smokers unwilling to change their behaviour, ${ }^{34} 35$ and may be overemphasised in observation/case studies, simply because it is so observable and triggers counterargument. Regardless, promotion of smoke-free workplaces should address conflict resolution, and model programmes do this. ${ }^{20} 31$

This study highlights opportunities for gain-based messaging (eg, increased productivity) to promote smokefree workplaces, consistent with model interventions in other blue-collar settings. ${ }^{20} 28$ Another opportunity is the commercial advantage of appealing to non-smoking clients (which has been discussed more often in the hospitality sector ${ }^{36}{ }^{37}$ ) and to non-smoking employees.

Suggestions for policy implementation include: clear definitions; management commitment and enforcement; and planning for covert smoking. These are consistent with recommendations from research with tradespersons ${ }^{20}$ and other workplaces late to adopt smoking bans such as mental health facilities ${ }^{29} 31$ and the military. ${ }^{38}$ Definitional challenges remain. Enclosed space rules defined for restaurants may not apply. ${ }^{39} 40$ Unlike doorways, ${ }^{41}$ perimeters around non-smoking coworkers would be a moving target and even more difficult to enforce. It was unclear to these workers what stage of completion marked when a building under construction became an indoor workplace. Complete grounds bans are appearing in many settings ${ }^{42}$ and this would eliminate the grey area.

Little evidence was found that builders need to be told that SHS is linked to health effects. Instead, they wanted detailed scientific data on dose and risk thresholds-particularly outdoors. Vague or poorly substantiated statements about SHS should be avoided in light of a critical audience, even among non-smokers. This presents challenges for knowledge exchange and basic research. High toxin concentrations are found from cigarette smoke in naturalistic outdoor settings. ${ }^{43} 44$ Regardless, it is difficult to estimate personal exposure outdoors, which depends on the number of cigarettes, distance and air movement, all of which are highly variable. ${ }^{44}$

A goal of smokefree workplaces may be to reduce smoking prevalence. ${ }^{45}$ Further research should explore how to maximise this outcome in blue-collar populations, ${ }^{46} 47$ where it is challenging to offer multicomponent interventions. ${ }^{48}$ Current and former smokers recognised that smoking at work made it hard to quit and stay quit. Again, complete site bans, as opposed to smoking areas, may be most effective. ${ }^{45}$

The motivation to hire non-smokers deserves attention. Shutting smokers out of work will not improve an inequitable situation where lower occupational status and unemployment are associated with high tobacco-related health burden, and smokers remain economically disadvantaged. ${ }^{5} 649$ Working tradespersons already have poorer access to cessation supports and services. ${ }^{1050}$ Creative means are needed to connect builders with effective cessation supports. One model used has been to 


\section{What this study adds}

Smoking and smoking at work were not universally accepted among this group of workers. Many people working in home building, renovation, and construction prefer a smoke-free workplace.

- At least some employers in this sector are acting upon a preference to hire non-smokers. This has implications for the economic burden associated with smoking and underscores the importance of helping blue collar workers to quit without relying on work-related health programs and insurance.

- Blue collar workers may not readily be convinced by arguments to restrict second hand smoke based on the precautionary principle. Further research is warranted to develop effective risk communication strategies.

combine health promotion with job training. ${ }^{28} 51$ Another is to connect blue-collar workers with effective population-wide interventions ranging from brief assessment and referral to individual support and pharmacotherapy. ${ }^{52-54}$

An opportunity exists to facilitate smoking bans in construction, following on success in other challenging workplaces. Reaching blue-collar workers with successful cessation interventions remain a challenge and every opportunity to reach this population should be explored.

Acknowledgements We would like to acknowledge the contributions of Phil Bigelow, Lori Diemert, Pam Kaufman and Sabrina Voci for assistance with this research and comments on the draft manuscript.

Funding This research was supported by the Ontario Tobacco Research Unit, which receives funding from the Ontario Ministry of Health Promotion.

\section{Competing interests None}

Ethics approval This study was conducted with the approval of the University of Toronto Health Sciences Research Ethics Board (expressed waiver of requirement for full review on the grounds that the research involved only anonymised publicly available data).

Contributors SB conceived of the study, identified the data source, and took primary responsibility for integration of findings with prior literature. Both authors contributed to development of the data analysis strategy. KB developed the initial codes and structures for major and minor discussion themes. Both authors participated in data analysis, interpretation, and manuscript preparation.

Provenance and peer review Not commissioned; externally peer reviewed.

\section{REFERENCES}

1. Bang KM, Kim JH. Prevalence of cigarette smoking by occupation and industry in the United States. Am J Ind Med 2001;40:233-9.

2. Dalhgren G, Whitehead M. European Strategies for Tackling Social Inequities in health: Levelling up. Part II: a Discussion Paper on European Strategies for Tackling Social Inequities in Health. Copenhagen: World Health Organization, 2006

3. Giovino GA, Pederson LL, Tosclair A. The Prevalence of Selected Cigarette Smoking Behaviors by Occupational Class in the United States. Work, smoking, and health A NIOSH Scientific Workshop NIOSH Publication No 2002-148. Washington DC: National Institute for Occupational Safety and Health (NIOSH), 2002:22-31.

4. Lee DJ, Fleming LE, Arheart KL, et al. Smoking rate trends in U.S. occupational groups: the 1987 to 2004 National Health Interview Survey. J Occup Environ Med 2007:49:75-81

5. Main C, Thomas S, Ogilvie D, et al. Population tobacco control interventions and their effects on social inequalities in smoking: placing an equity lens on existing systematic reviews. BMC Public Health 2008;8:178.

6. Substance Abuse and Mental Health Services Administration Office of Applied Studies. NSDUH Report: Cigarette Use Among Adults Employed Full Time, by Occupational Category. Rockville, MD: Substance Abuse and Mental Health Services Administration, 2009.

7. Physicians for a Smoke-Free Canada. Smoking in Canada: A Statistical Snapshot of Canadian Smokers. Ottawa: Physicians for a Smoke-Free Canada, 2005.
8. Schwartz R, O'Connor S, Minian N, et al. Evidence to Inform Smoking Cessation Policymaking in Ontario. Toronto: Ontario Tobacco Research Unit, 2009.

9. Barbeau EM, Krieger N, Soobader M-J. Working class matters: socioeconomic disadvantage, race/ethnicity, gender, and smoking in NHIS 2000 [Erratum appears in 2004 Aug;94(8):1295]. Am J Public Health 2004:94:269-78

10. Lee DJ, Fleming LE, McCollister $\mathrm{KE}$, et al. Healthcare provider smoking cessation advice among US worker groups. Tobacco Control 2007;16:325-8.

11. Barbeau EM, McLellan D, Levenstein C, et al. Reducing occupation-based disparities related to tobacco: roles for occupational health and organized labor. Am J Ind Med 2004;46:170-9.

12. Frankish CJ, Johnson JL, Ratner PA, et al. Relationship of organizational characteristics of Canadian workplaces to anti-smoking initiatives. Preventive Medicine 1997;26:248-56.

13. Sorensen G. Worksite tobacco control programs: the role of occupational health. Respir Physiol 2001;128:89-102.

14. Sorensen G, Barbeau EM. Integrating occupational health, safety and worksite health promotion: opportunities for research and practice. Medicina del Lavoro 2006;97:240-57

15. Sorensen G, Emmons K, Stoddard AM, et al. Do social influences contribute to occupational differences in quitting smoking and attitudes toward quitting? Am J Health Promot 2002;16:135-41.

16. United States Department of Commerce. U.S. Census Bureau News: April 2010 Construction at \$869.1 Billion Annual Rate. Washington, DC: U.S. Department of Commerce, 2010

17. Bigelow PL, Gilkey DP, Greenstein $\mathrm{S}$, et al. Evaluation of HomeSafe: An injury and illness prevention program in residential construction. Occupational Health and Industrial Medicine 1998:39:168.

18. Kidd P, Parshall $\mathrm{M}$, Wojcik $\mathrm{S}$, et al. Overcoming recruitment challenges in construction safety intervention research. Am J Ind Med 2004;45:297-304.

19. Barbeau EM. Addressing class-based disparities related to tobacco: working with labor unions. Cancer Causes Control 2001;12:91-3.

20. Barbeau EM, Delaurier G, Kelder G, et al. A decade of work on organized labor and tobacco control: reflections on research and coalition building in the United States. J Public Health Policy 2007;28:118-35.

21. The Taunton Press Incorporated. Breaktime (Discussion Forum) http://forums finehomebuilding.com/ Newtown, CT: The Taunton Press.

22. Taunton Press Incorporated. Fine Homebuilding Media Kit. Newtown, CT: Taunton Press Incorporated.

23. Creswell J. Qualitative Inquiry and Research Design: Choosing Among Five Approaches. 2nd edn. Thousand Oaks, CA: SAGE Publications, 2007.

24. Strauss A, Corbin J. Basics of Qualitative Research: Grounded Theory Procedures and Techniques. Newbury Park, CA: SAGE Publications Inc., 1990.

25. Maxwell JA. Qualitative Research Design: An Interactive Approach. 2nd edn. Thousand Oaks, CA: SAGE Publications, 2005.

26. Vaughn S, Shay Schunn J, Sinagub J. Focus Group Interviews in Education and Psychology. Thousand Oaks, CA: SAGE Publishers, 1996

27. Labor Statistics Bureau. Occupational Outlook Handbook, 2010-11. Labor Statistics Bureau Bulletin 2800. Washington: US Department of Labor, Labor Statistics Bureau, 2010.

28. Okechukwu CA, Krieger N, Sorensen G, et al. MassBuilt: effectiveness of an apprenticeship site-based smoking cessation intervention for unionized building trades workers. Cancer Causes Control 2009;20:887-94.

29. El-Guebaly N, Cathcart J, Currie S, et al. Public health and therapeutic aspects of smoking bans in mental health and addiction settings. Psychiatr Serv 2002:53:1617-22.

30. Hempel AG, Kownacki R, Malin DH, et al. Effect of a total smoking ban in a maximum security psychiatric hospital. Behav Sci Law 2002;20:507-22.

31. Voci S, Bondy S, Zawertailo L, et al. Impact of a smoke-free policy in a large psychiatric hospital on staff attitudes and patient behavior. General Hospital Psychiatry 2010:32:623-30

32. Morreall J. Applications of humor: Health, the workplace, and education. In: Raskin V, ed. The Primer of Humor Research. New York: Mouton de Gruyter 2008:449-78.

33. Holmes J. Sharing a laugh: pragmatic aspects of humor and gender in the workplace. J Pragmat 2006;38:26-50.

34. Coleman T, Stevenson K, Wilson A. A new method for describing smokers' consulting behaviours which indicate their motivation to stop smoking: an exploration of validity and reliability [Erratum appears in Fam Pract 2002 Aug;19(4):432]. Fam Pract 2002;19:154-60.

35. Coleman T, Stevenson K, Wilson A. Using content analysis of video-recorded consultations to identify smokers" "readiness" and "resistance" towards stopping smoking. Patient Educ Couns 2000;41:305-11.

36. Borland R, Yong HH, Siahpush M, et al. Support for and reported compliance with smoke-free restaurants and bars by smokers in four countries: findings from the International Tobacco Control (ITC) Four Country Survey. Tobacco control 2006;15 (Suppl 3):iii34-41.

37. Hilton S, Cameron J, MacLean A, et al. Observations from behind the bar: changing patrons' behaviours in response to smoke-free legislation in Scotland. BMC Public Health 2008:8:238.

38. Jahnke SA, Haddock CK, Poston WSC, et al. A qualitative analysis of the tobacco control climate in the U.S. military. Nicotine Tob Res 2010;12:88-95. 
39. Thomson G, Wilson N, Edwards R. At the frontier of tobacco control: a brief review of public attitudes toward smoke-free outdoor places. Nicotine Tob Res 2009;11:584-90.

40. Kennedy RD, Elton-Marshall T, Mutti $S$, et al. Understanding the impact of the Smoke-Free Ontario Act on hospitality establishments' outdoor environments: a survey of restaurants and bars. Tobacco Control 2010:19:165-7.

41. Harris KJ, Stearns JN, Kovach RG, et al. Enforcing an outdoor smoking ban on a college campus: effects of a multicomponent approach. J Am Coll Health 2009;58:121-6

42. Kunyk D, Els C, Predy G, et al. Development and introduction of a comprehensive tobacco control policy in a Canadian regional health authority. Preventing Chronic Disease 2007:4:A30.

43. Cameron M, Brennan E, Durkin S, et al. Secondhand smoke exposure (PM2.5) in outdoor dining areas and its correlates. Tobacco Control 2010:19:19-23

44. Klepeis NE, Ott WR, Switzer P. Real-time measurement of outdoor tobacco smoke particles. J Air Waste Manag Assoc 2007:57:522-34.

45. Fichtenberg CM, Glantz SA. Effect of smoke-free workplaces on smoking behaviour: systematic review. BMJ 2002;325:188.

46. Bell K, McCullough L, Devries K, et al. Location restrictions on smoking: assessing their differential impacts and consequences in the workplace. Can J Public Health 2009;100:46-50.
47. Cahill K, Moher M, Lancaster T. Workplace interventions for smoking cessation. Cochrane Database Syst Rev 2008;(4):CD003440.

48. Hunt MK, Lederman R, Stoddard AM, et al. Process evaluation of an integrated health promotion/occupational health model in WellWorks-2. Health Education \& Behavior 2005;32:10-26.

49. Jha $\mathbf{P}$, Peto R, Zatonski W, et al. Social inequalities in male mortality, and in male mortality from smoking: indirect estimation from national death rates in England and Wales, Poland, and North America. Lancet 2006;368:367-70.

50. Krieger N, Barbeau EM, Soobader M-J. Class matters: U.S. versus U.K. measures of occupational disparities in access to health services and health status in the 2000 U.S. National Health Interview Survey. Int J Health Serv 2005;35:213-36.

51. Dahlstrom K, Ney T. Blue-collar taste: researching strategies to shift the smoking norms in trades workers Visions. BC's Mental Health and Addictions Journal 2007:3:21-2.

52. Tinkelman D, Wilson SM, Willett J, et al. Offering free NRT through a tobacco quitline: impact on utilisation and quit rates. Tobacco Control 2007;16(Suppl 1):i42-6.

53. Bock BC, Graham AL, Whiteley JA, et al. A review of web-assisted tobacco interventions (WATIs). J Med Internet Res 2008;10:e39.

54. Miller N, Frieden TR, Liu SY, et al. Effectiveness of a large-scale distribution programme of free nicotine patches: a prospective evaluation. Lancet 2005; $365: 1849-54$

\section{DIFFERENTIAL DIAGNOSIS}

\section{Trustworthy guidance on your iPhone}

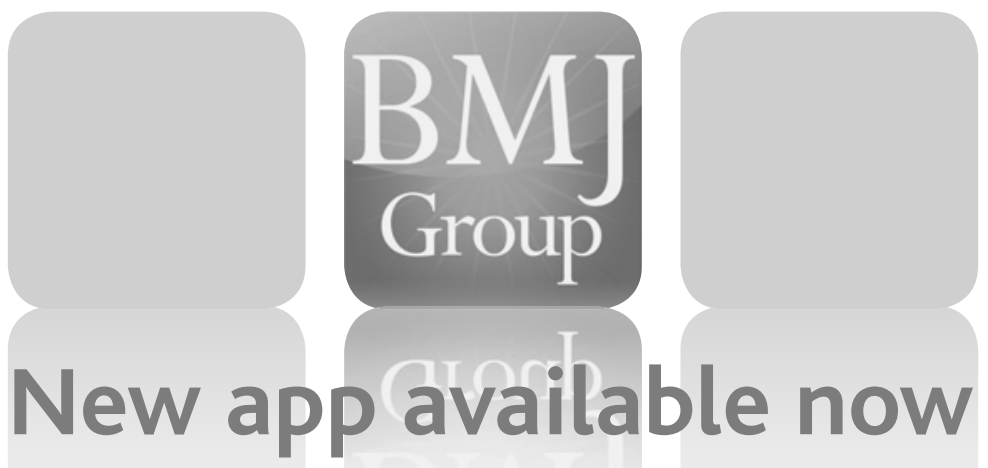

Find out more at bestpractice.bmj.com/differentials 